International Journal of Engineering \& Technology, $7(1.5)(2018) 264-268$
International Journal of Engineering \& Technology
SPC
Website: www.sciencepubco.com/index.php/IJET
Research paper

\title{
Extensive analysis of slip power recovery scheme
}

\author{
Ratansingh Atkar ${ }^{1 *}$, B. Chandramouli ${ }^{2}$ \\ ${ }^{1}$ Assistant professor in AMBO University, Ethiopia. \\ ${ }^{2}$ Assistant professor in Adama Science and Technology University, Ethiopia. \\ *Corresponding author E-mail: ratansingh.atkar@gmail.com
}

\begin{abstract}
Enlistment engines square measure the foremost typically used engines in mechanical movement management frameworks. The slip management healing conspire (SPRS) offers speed management of connective hitch engine (SRIM) below synchronous speed. The slip management healing drives is employed as a neighborhood of huge limit pumps and fan drives, shipboards VSCF (variablespeed/consistent recurrence) frameworks, variable-speed hydro pumps/generators thus forth. throughout this paper Associate in Nursing thorough investigation of slip management healing conspire is displayed. reproduction of the originated is finished utilizing MATLAB/SIMULINK condition and trial established is prepared up at intervals the centre for a 2 H.P. engine. The trial and reproduction comes concerning square measure investigated.
\end{abstract}

Key words: Analysis, Feedback Power, Simulation, Slip control recuperation plot, Matlab/Simulink

\section{Introduction}

To control the speed of SRIM with higher efficiency and better performance, a shot was created by Scherbius and Kramer to exchange the additional resistances from the rotor circuit with the help of recovered rotor slip power exploitation auxiliary machines. This contend an enormous role in enhancing the event of electrical drive systems exploitation induction motors. Use of static convertor inside the rotor circuit was planned by Lavi et al in 1966 for the speed management of SRIM in sub synchronous vary. The theme comprising of bridge rectifier in rotor circuit, filter device, line commutated bridge convertor and recovery device as indicated in Fig.

1. Since then varied modifications inside the planned theme were created by varied authors as expressed inside the literature.

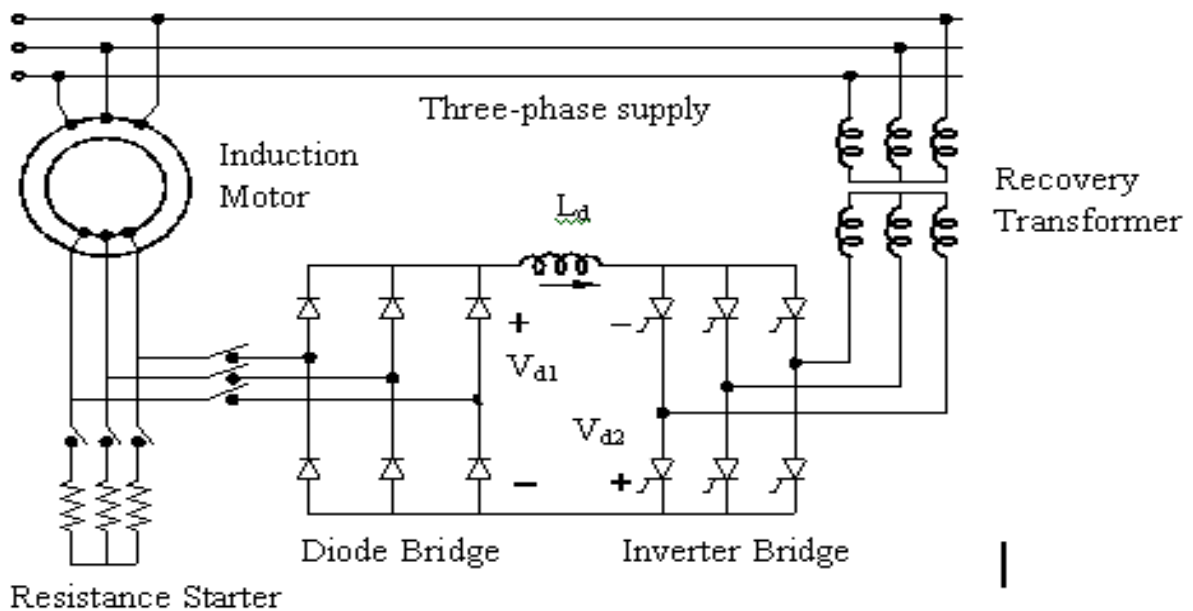

Rotor Resistance Starter

Fig. 1. Basic slip power recovery scheme

In this paper, a comprehensive analysis of slip power recovery theme is given. The theme is simulated exploitation MATLAB/SIMULINK setting. The results square measure valid with the experimental set-up results exploitation microcontroller as firing angle controller for the converter circuit. The advantage of exploitation microcontroller over digital and semiconductor device techniques square measure it's versatile, simple, economical, and consumes less hardware throughout this work, steady state relationships between converter firing angle force, speed, and device current for the SPRS square measure derived. it has been determined that the drive offers linear torque- current relationship form of a severally excited DC motor. 


\section{Performance analysis of scheme}

The basic slip power recovery theme mistreatment static Kramer drive is shown in Fig. 1. throughout this theme a voltage ViR is applied to the connective terminals, in section with the rotor current through recovery device \&amp; line commutated converter. that the effective equivalent circuit of the drive is delineated as:

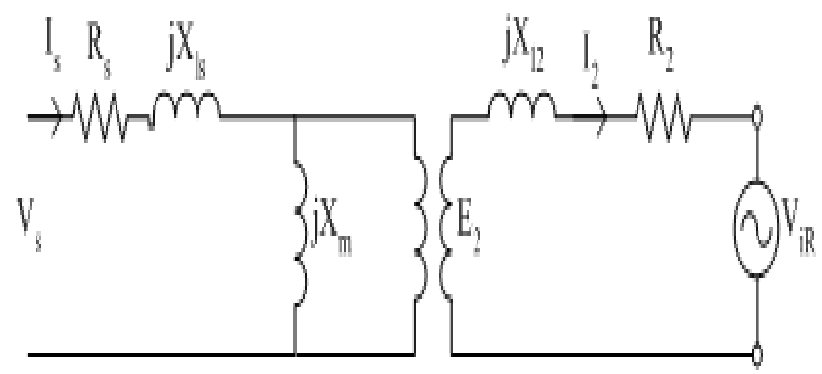

Fig. 2. Voltage injection in rotor circuit

The injected voltage can be referred to the stator as:

$$
V_{i}=\frac{V_{i R}}{a_{e f f}}
$$

Above equation gives the following equivalent circuit:

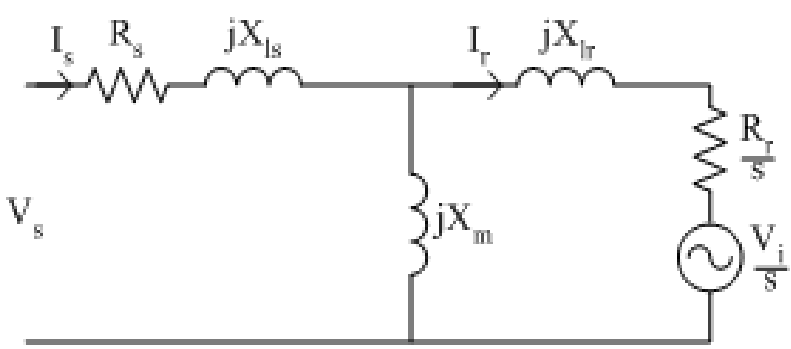

Fig. 3. Equivalent circuit refer to Stator

Considering the given equivalent circuit, if the injected voltage is $\mathrm{Vi} / \mathrm{s}$ increased, the rotor current $\mathrm{Ir}$ ar reduced, resulting in a reduction at intervals the on the market torsion generated by the motor. If there is a load applied to the motor, the rotor will block, resulting in an increase in slip. As slip can increase, the effective voltage seen by the computer ar reduced (the actual voltage physically induced at intervals the rotor, due to the computer, will increase). As a result, rotor current will increase. this permits the machine to hunt out a fresh steady state position where the induced rotor current produces enough torsion to equal the load torsion but at a reduced speed.

\subsection{Exploration of operation}

To change the analysis, assumptive that the magnetizing physical phenomenon is affected to the terminals of the equivalent circuit. (Otherwise, the computer half voltage, computer physical phenomenon and magnetizing physical phenomenon are going to be replaced by a The venin equivalent provide and physical phenomenon.).

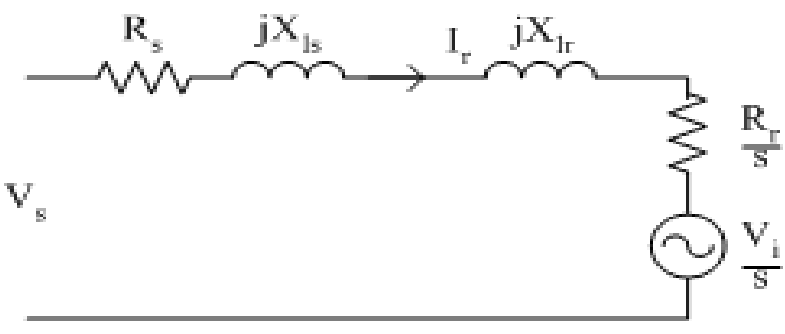

Fig. 4: Approximate equivalent circuit refer to Stator

If the injected voltage is in section with the rotor current, then the voltages among the equivalent circuit is additionally written as:

$$
\begin{gathered}
V_{s}=\overrightarrow{I_{R}}\left(R_{S+} \frac{R_{R}}{S}\right)+\frac{\vec{V}_{i}}{S}+j \vec{I}_{R}\left(X_{I S}+X_{I \gamma}\right) \\
V_{S}=\frac{I_{\gamma} R_{\gamma}+V_{i}}{S} \angle \theta_{\gamma}+I_{\gamma}\left(X_{I S}+X_{I \gamma}\right) \angle\left(\theta_{\gamma}+90^{\circ}\right) \\
V_{S}^{2}=\left(I_{\gamma} R_{S}+\frac{I_{\gamma} R_{\gamma}+V_{i}}{S}\right)^{2}+I_{\gamma}^{2}\left(X_{I S}+X_{I \gamma}\right)^{2}
\end{gathered}
$$

Re-arranging, the slip may be found as

$$
S=\frac{V_{i}+I_{\gamma} R_{\gamma}}{\left(V_{s}^{2}-I_{\gamma}^{2}\left(X_{I S}+X_{I \gamma}\right)^{2}\right)^{1 / 2}-I_{\gamma} R_{S}}
$$

\section{Power and Torque}

The air gap power of the machine may be written as

$$
P_{\text {gap }}=3 I_{\gamma} \frac{\left(I_{\gamma} R_{\gamma}+V_{i}\right)}{S}
$$

Breaking this equation into components, it will be seen that the air gap power is that the total of rotor resistive losses, power recovered through the slip rings and therefore the mechanical power made.

$$
\mathrm{P}_{\text {gap }}=3 \mathrm{I}^{2}{ }_{\gamma} \mathrm{R}_{\gamma}+3 \mathrm{I}_{\gamma} \mathrm{V}_{\mathrm{i}}+3 \mathrm{I}_{\gamma}\left(\mathrm{I}_{\gamma} \mathrm{R}_{\gamma}+\mathrm{V}_{\mathrm{i}}\right) \frac{(1-\mathrm{s})}{\mathrm{s}}
$$

Using the expression for air gap power, the torque may be written as

$$
\tau=3 I_{\gamma} \frac{\left(I_{\gamma} R_{\gamma}+V_{i}\right)}{s \omega_{s}}
$$

Now, subbing the slip expression into the torsion expression offers the result that torsion is barely a perform of rotor current, not slip or injected voltage:

$$
\tau=\frac{3 \mathrm{I}_{\gamma}}{\omega \mathrm{S}}\left[\left(\mathrm{V}_{\mathrm{s}}^{2}-\mathrm{I}_{\gamma}^{2}\left(\mathrm{X}_{\mathrm{Is}}+\mathrm{X}_{\gamma}\right)^{2}\right)^{1 / 2}-\mathrm{I}_{\gamma} \mathrm{R}_{\mathrm{s}}\right]
$$

The expression on top of means for a given force, the rotor current can forever be constant, freelance of speed.

The voltage at the input to the diode rectifier is given by:

$$
V_{L L i R}=\sqrt{3} \frac{V_{i}}{a_{e f f}}
$$

The dc link voltage can be found from the diode input line-line voltage as:

$$
V_{D C}=\frac{3 \sqrt{2}}{\pi} V_{L L i R}
$$

Considering the thyristor device, this circuit may be thought of as a thyristor rectifier connected in reverse, and therefore the DC link voltage is expounded to the line-line electrical converter voltage as:

$$
V_{D C}=-\frac{3 \sqrt{2}}{\pi} V_{L L i x \gamma} \cos \alpha=\frac{3 \sqrt{2}}{\pi} V_{L L i x \gamma}|\cos \alpha|
$$


Substituting the above expressions, the voltage injected into the rotor can be calculated as:

$$
V_{i}=\frac{a_{e f f}}{\sqrt{3}} V_{L L i n v}|\cos \alpha|
$$

In the case that the electrical converter line-line voltage is connected to the availability through a electrical device, as shown within the diagram higher than, the injected voltage is involving the availability voltage as:

$$
V_{i}=\frac{a_{\text {eff }}}{\sqrt{3}} \frac{N_{\text {inv }}}{N_{\text {Line }}} V_{L L S}|\cos \alpha|
$$

Using this simplified analysis along side the slip power recovery force equations, the thyristor firing angle needed for a selected force at a selected speed may be found.

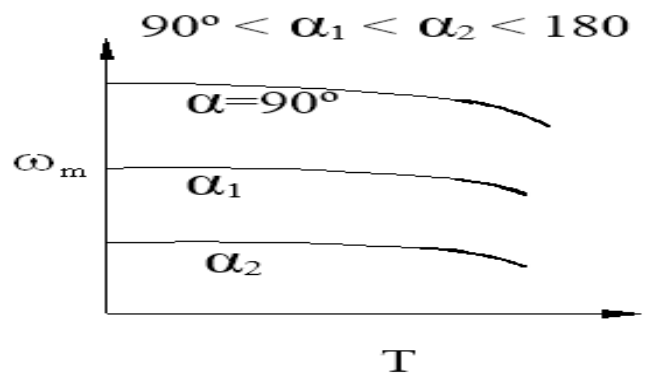

Fig. 5: Torque-speed characteristics of the drive

\section{No-Load Condition}

Consider again the expression for slip:

$$
S=\frac{V_{i}+I_{\gamma} R_{\gamma}}{\left(V_{S}^{2}-I_{\gamma}^{2}\left(X_{I S}+X_{I \gamma}\right)^{2}\right)^{1 / 2}-I_{\gamma} R_{S}}
$$

If the torque is zero, then the rotor current will also be zero and at zero torque, the slip is given by:

\section{Efficiency}

$$
S_{O}=\frac{V_{i}}{V_{s}}
$$

Since variety of the flexibility equipped to the motor is recovered from the rotor circuit, the efficiency cannot be calculated as just output power over input power. Instead, in associate degree passing slip power recovery drive the efficiency is:

$$
\eta=\frac{P_{\text {out }}}{P_{\text {in }}-P_{\text {recovered }}}
$$

Here, $\boldsymbol{P}$ recovered is the effective recovered power at the stator coil terminals. because the power recovered from the rotor is feedback to the stator coil once more, the drive has higher potency as compared to rotor resistance methodology.

\section{Experimental Set-Up \& implementation of scheme}

For developing the experimental set-up, power diodes \&amp; thyristors of sixteen amperes area unit used for the device and line commutated convertor circuits severally. A filter inductance of twenty $5 \mathrm{mH}$ has been connected. The experimental set-up of the firing circuit of the drive is microcontroller based. Three vary of single-phase; star-star connected decrease transformers area unit accustomed get synchronous reference signals from the provision. The signal procurable from each electrical device has been fed to a high gain operational equipment LM324 consisting of fourfreelance internal channels. The zero crossing of each half is detected here and so the quadrangle output signals from LM324 square measure fed to the microcontroller unit. Low power, high performance forty pin, CMOS, 8-bit microcontroller Micro- controller ATMEL AT89S52 has been accustomed end up firing pulses

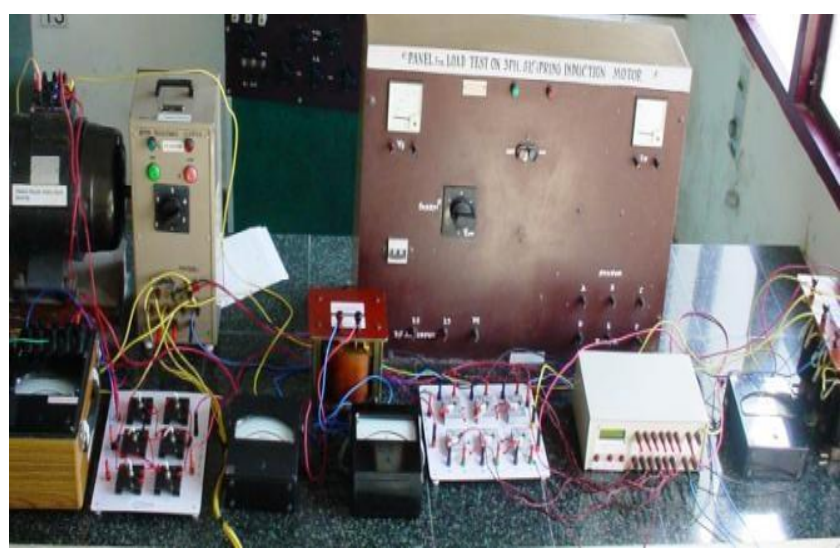

Fig. 6: Experimental Set-up of the Scheme

\section{Simulation of Scheme}

To study the performance of the drive, a simulation block-set in Matlab/Simulink has been implemented as shown in Figure seven. A $2 \mathrm{HP}, 400 \mathrm{~V}$, fifty cycle wound rotor induction motor has been used for the simulation. Provision has been created to measure mechanical device current, speed and force of the motor. The active and reactive power input of the motor, the recovery device and additionally the availability ar measured exploitation P-Q block. Provision has jointly been created to measure fully completely different voltages and currents of the theme wherever required. the data has been saved to the area for any analysis. various parameters of the model ar given in Appendix-A.

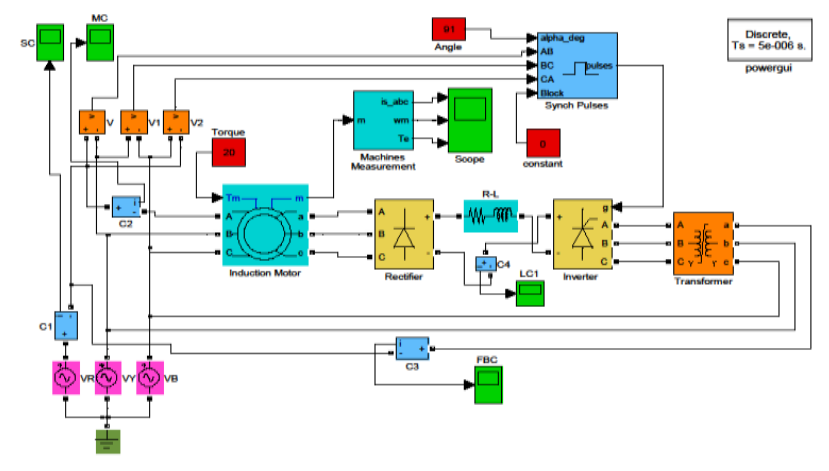

Fig. 7. Simulation circuit for slip power recovery scheme

\section{Simulated \& experimental results}

\subsection{Results \& analysis of simulation work}

Simulation results show that by varied firing angle (above ninety degree in very little intervals), motor speed is also controlled from zero to nominal speed. The motor speed vs. time characteristics at two completely completely different firing angles square measure shown in Figure eight. it's going to be discovered that steady state speed for higher firing angle could be a smaller quantity as compared to lower firing angle. The upper value of firing angle is restricted to $165^{\circ}$ for the safe commutation of thyristors [16]. 


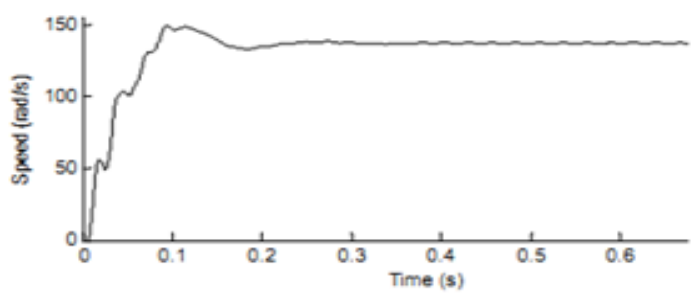

(a)

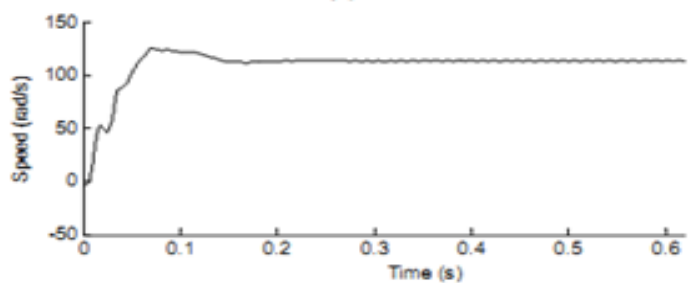

(b)

Fig. 8. Motor Speed at a) 92 degree

\subsection{0-degree firing angle}

Moreover, convertor circuit consumes negative active power and positive reactive power from line aspect as shown in Figure 9. this implies that active power is came back to the network, but associate outsized amount of reactive power is absorbed from the provision. as a result of the reactive power consumption, the power issue of the theme becomes low.

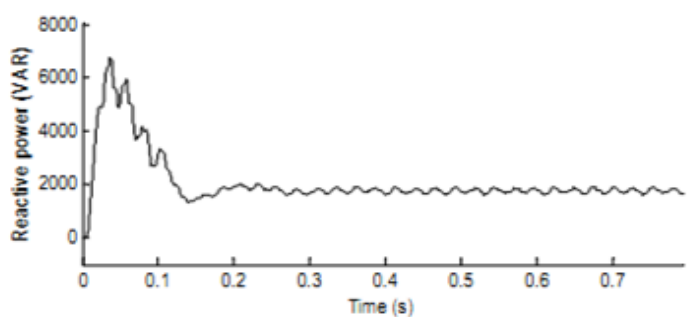

(a)

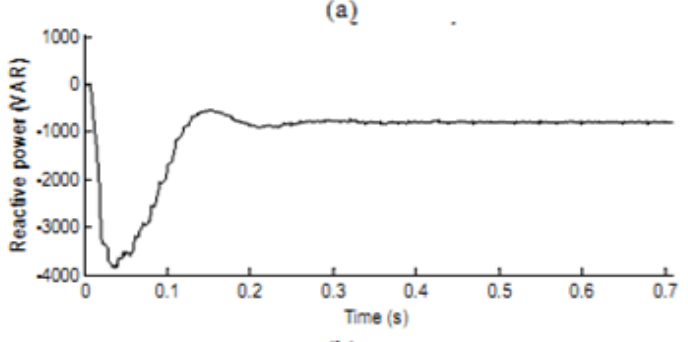

(b)

Fig. 9. Reactive power taken by a) motor

\subsection{Inverter}

The presence of power device and convertor circuit throughout this method, in addition cause low frequency odd harmonics (3rd, 5 th, seventh ...) injection to the supply network. Motor force, feedback current and provide current waveforms area unit shown in Figure 10.
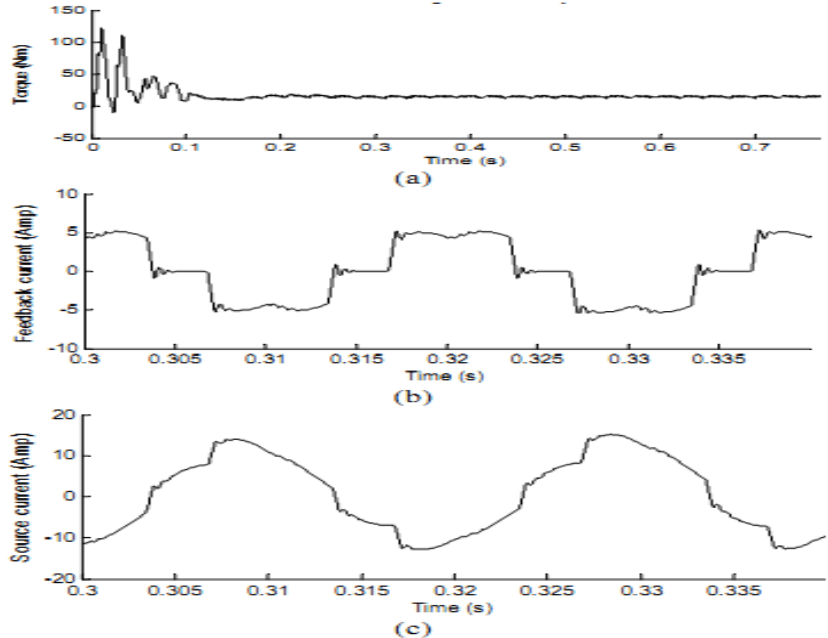

Fig.10: a) Motor torsion b) Feedback current

c) Source current

It ar usually discovered that torsion created by the motor is not constant but metrical. It will even be ascertained that the feedback current and additionally the availability current waveforms unit of measurement distorted. This leads to inflated force ripple and consequently motor temperature is inflated. The academic degree of the availability current has been found to be eleven.57\%. The non- incurvate stator and convertor feed-back current have a bearing on line-side current and injects harmonics at intervals the supply network.

Fast Fourier process (FFT) window of offer current wave kind has been shown in Figure eleven. It ar usually discovered that it consists of sub-harmonic love dc part, twenty 5 Hertz and multiple harmonics love higher order (third, fifth and seventh etc) harmonics.

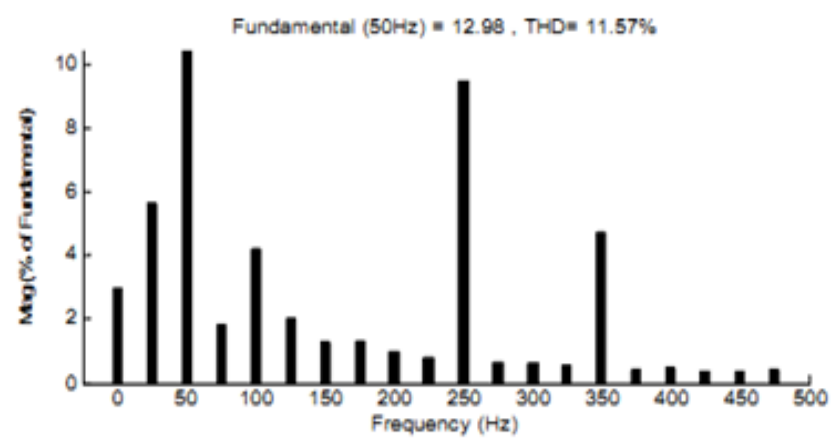

Fig.11: FFT Analysis of provide current

It may be any discovered that, fifth and seventh harmonics ar the dominant one.

Results \&amp; analysis of Experimental work:

The performance characteristics of the drive have in addition been analyzed pattern the experimental set-up. The variation of the rotor speed w.r.t. a) firing angle \&amp; b) inductance current has been shown in Figure twelve a) and twelve b) severally. 


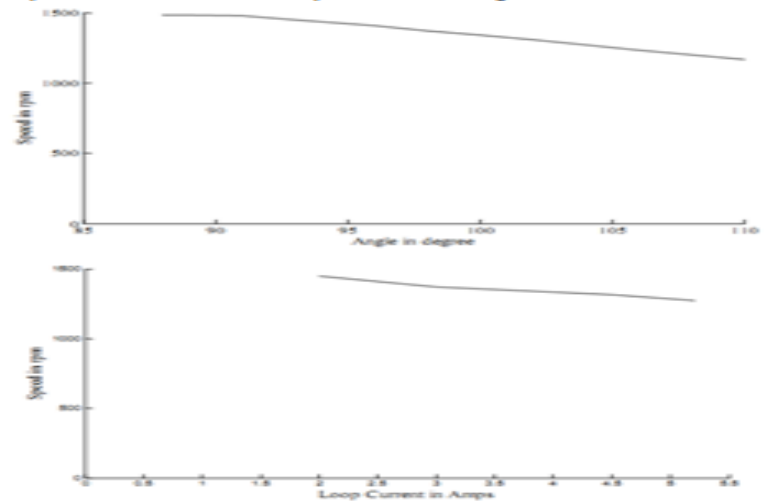

Fig.12. Variation of speed w.r.t a) firing angle

\subsection{Inductance current}

The input power of the drive with and whereas not slip power recovery has been shown in Figure 13. If we've got a bent to neglect the convertor and device losses, we'll notice that for an analogous load, the input power taken from the availability with slip power recovery theme could be a smaller quantity than that of power consumed whereas not slip power recovery theme.

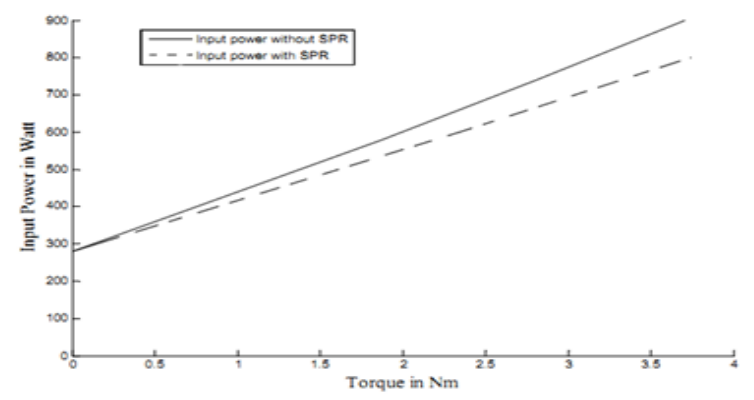

Fig. 13. Input power of drive

Hence AN overall increase in potency is obtained.

\section{Conclusions}

In this paper, the slip power recovery methodology for the speed management of three-phase connective induction motor has been investigated. The performance equations area unit drawn and a simulation block-set model in Matlab/Simulink has been enforced. A microcontroller based open-loop speed management experimental set-up has jointly been developed inside the laboratory. the following conclusions area unit drawn from the study:

1. The torsion of the drive varies linearly with the dc link current. Hence, the drive has similar characteristics as that of severally excited dc motor.

2. The increase in efficiency has been determined as compared to rotor resistance methodology of speed management.

3. The simulation/experimental results show the overall reduced power issue of the drive.

4. Presence of device and line commutated converter results in harmonic injection on the provision side.

5. Presence of current harmonics in stator and rotor windings causes further heating of motor. Thus, de-rating of the drive is required for constant load as compared to rotor resistance management technique.

\section{Appendix-A}

Slip ring induction motor: 3-phase, $2 \mathrm{HP}, 400$ volt, amps, $50 \mathrm{~Hz}$, 1440 rpm, Y-Y connected. Parameters: mechanical device resistance $=$ four. $8 \Omega$; Rotor resistance $=4.2 \Omega$; Stator leakage reactance $=9.5 \Omega$; Rotor leakage reactance $=9.5 \Omega$; Magnetizing reactance $=185 \Omega ;$ Stator to rotor turn ratio $=5$. Magneti

\section{Other Parameters of the drive system:}

Turns relation of recovery device (inverter to line side) = zero. 2 ; Resistance of smoothing inductor $=2 \Omega$; Inductance of smoothing inductor $=0.025 \mathrm{H}$

\section{References}

[1] Lavi, R.J. Polge, "Induction Motor Speed Control with Static Inverters in the Rotor", IEEE Transactions on Power Apparatus and Systems, Vol. PAS-85, No. 1, Jan 1966, pp. 76-84

[2] W Shepherd, J Stanway, "Slip Power Recovery in an Induction Motor by the use of a Thyristor Inverter", IEEE Transaction on Industry and General Applications, Vol. IGA-5, No. 1, Jan/Feb 1969, pp. 74-82.

[3] W Shepherd and A.Q. Khalil, "Capacitive, Compensation of Thyristor Controlled Slip- Energy Recovery System", Proceedings IEEE, Vol. 117, No. 5, May 1970, pp. 948-956.

[4] S.K. Pillai, K.M. Desai, "A Static Sherbius Drive with Chopper", IEEE Transaction on Industrial Electronics and Control Industrial Instrumentation, Vol. IEC-24, No. 1, Feb 1977, pp. 24-29.

[5] V.N. Mittle, K. Venkatesan, S.C. Gupta, "Switching Transient in Static Slip-Energy Recovery Drive", IEEE Transaction Power Apparatus and System, Vol. 98, July/August 1979, pp. 13151320

[6] K. Taniguchi, H. Mori, "Application of a Power Chopper to the Thyristor Scherbius", IEEE Proceedings, Vol. 133, Pt. B, No. 4, July 1986, pp. 225-229.

[7] M.S. Hilderbrandt, "Reference Frame Theory applied to the Analysis of a Slip-Recovery system”, Purudue University 1986.

[8] B.A.T. Al Zahawi, B.L. Jones, W. Drury, "Effect of Rotor rectifier on motor performance in Slip Energy drives", Canadian Electrical Engineering Journal, Vol. 13, No. 1, 1987.

[9] S.R. Doradla, S. Chakravorty, K.E. Hole, "A new Slip Power Recovery Scheme with Improved Supply Power Factor”, IEEE Transaction on Power Electronics, Vol. 3, No. 2, April 1988, pp 200-207.

[10] Maria G. Ioannides, John A. Tegopoulos, "optimal efficiency Slip-Power Recovery Drive", IEEE Transactions on Energy conversion, Vol. 3, No. 2, June 1988.

[11] G.D. Marques, "Synthesis of active and reactive Power Controllers for the Slip Power Recovery drive", in Proceedings EPE 1989, Vol. 2, Aachen, Germany, Oct. 1989, pp. 829- 833.

[12] E. Akpinar, P. Pillay, "Modeling and Performance of Slip Energy Recovery Induction Motor drive", IEEE Transaction on Energy Conversion, Vol. 5, No. 1, March 1990.

[13] Maria G. Ioannides, John A. Tegopoulos, "Generalized Optimization Slip Power Recovery drives", IEEE Transaction on Energy Conversion, Vol. 5, No. 1, March 1990.

[14] Y. Baghzouz, M. Azam, "Harmonic Analysis of Slip Power Recovery Drives", 90/CH 2935-5/90/0000 (C 1990 IEEE.

[15] F. Liao, J.I. Sheng, A.L. Thomas, "A New Energy Recovery Scheme for Doubly fed, Adjustable-Speed Induction Motor drives", IEEE transaction on Industry Applications, Vol. IA-27, No. 4, July/Aug. 1991, pp. 728- 733

[16] Fundamentals of Electrical Drives, G. K. Dubey, 2002

[17] S.V.Manikanthan and T.Padmapriya "Recent Trends In M2m Communications In $4 \mathrm{~g}$ Networks And Evolution Towards $5 \mathrm{~g}$ 'International Journal of Pure and Applied Mathematics, ISSN NO:1314-3395, Vol-115, Issue -8, Sep 2017

[18] T.Padmapriya, Ms. N. Dhivya, Ms U. Udhayamathi, "Minimizing Communication Cost In Wireless Sensor Networks To Avoid Packet Retransmission", International Innovative Research Journal of Engineering and Technology, Vol. 2, Special Issue, pp. 38-42. 